\title{
College English Classroom Teaching Model from the Perspective of MOOC
}

\author{
Liu Xiaoyi \\ Foreign Language Department \\ Jilin Business and Technology College \\ Changchun, China \\ 182076127@qq.com
}

\begin{abstract}
The advent of the era of globalization and informatization not only changes our way of life but also changes the way we learn. The new study mode of MOOC has caused the wide attention of many people. Based on the concept of MOOC, it also applies to college English classroom teaching. In nature, MOOC pays more attention to the value of the subject, builds the associated chain of behavior and link the whole class. MOOC integrates excellent daily teaching resources and offers teaching changes in a new period. In college English teaching, creating MOOC mode can be a developing trend that can flipped classroom towards the future.
\end{abstract}

Keywords-MOOC; College English; Flipped classroom; Teaching mode

A massive open online course (MOOC) is an online course aimed at unlimited participation and open access via the web. In addition to traditional course materials such as filmed lectures, readings, and problem sets, many MOOCs provide interactive user forums to support community interactions among students, professors, and teaching assistants (TAs). MOOCs are a recent and widely researched development in distance education[1] which were first introduced in 2008 and emerged as a popular mode of learning in 2012.Early MOOCs often emphasized open-access features, such as open licensing of content, structure and learning goals, to promote the reuse and remixing of resources. Some later MOOCs use closed licenses for their course materials while maintaining free access for students. Robert Zemsky (2014) argues that they have passed their peak: "They came; they conquered very little; and now they face substantially diminished prospects." Others have pointed to a backlash arising from the tiny completion rates. With the rapid development of network technology, in recent years, MOOC construction and research is becoming a hot spot of online education at home and abroad. MOOC platforms, such as Coursera, Udacity and edX, grow rapidly in top universities at home and abroad and have launched their own MOOC courses. MOOC with its high-quality teaching resources has brought a new kind of revolutionary education paradigm in digital information era and has received the attention from higher education reformers. College foreign language teaching as one of the important basic disciplines of higher education, need to answer how to share MOOC innovative teaching mode as one of the important subjects.

This study focuses on the cognition internalization of the peculiar "flipped classroom" teaching English subject and formulates the neoteric process of teaching. Smooth interaction between teachers and students can be achieved in this process. Moreover, it can also stimulate potential interest and highlight the principal role of students. "Flipped classroom" is closely connected with MOOC, adding the category of colorful videos and focusing on encouraging creativity within classes. All kinds of colleges and universities should clear their own characteristics in order to select new model to improve the quality of teaching and highlight the unique teaching value of MOOC[2].

\section{BRIEF ANALYSIS OF MOOC CHARACTERISTICS}

MOOC, as a kind of online courses, is provided with the characteristics that other online courses do not have: (1) the course has rich content and high quality, which is the greatest feature of the MOOC different from other online courses.(2)the course is comprehensive and open to all learners because MOOC is adhering to the "sharing" concept and designed in order to offer more resources to more knowledge groups. MOOC is fully open in learning object, teaching form, teaching content, curriculum resources and teaching concept.(3) The powerful tool for compatible interaction is the third characteristic of MOOC, not only providing the online interactive tools, but can be used in an integrated MOOC system with interactive tools such as twitter, Facebook, WIKE and blog.

\section{The NeCESSity Of COLLEgE ENGLISH TO BUILD NEW TEACHING MODE WITH MOOC}

A course billed as "Asia's first MOOC” given by the Hong Kong University of Science and Technology through Coursera starting in April 2013 registered 17,000 students. About 60\% were from "rich countries" with many of the rest from middleincome countries in Asia, South Africa, Brazil or Mexico. Fewer students enrolled from areas with more limited access to the internet, and students from the People's Republic of China may have been discouraged by Chinese government policies. Koller stated in May 2013 that a majority of the people taking Coursera courses had already earned college degrees. According to a Stanford University study of a more general group of students "active learners" - anybody who participated beyond just registering - found that $64 \%$ of high school active learners were male and $88 \%$ were male for undergraduate- and graduate-level courses. A study from Stanford University's 
Learning Analytics group identified four types of students: auditors, who watched video throughout the course, but took few quizzes or exams; completers, who viewed most lectures and took part in most assessments; disengaged learners, who quickly dropped the course; and sampling learners, who might only occasionally watch lectures.[3]

Through the screening of the college entrance examination, students who enter the university campus are very good in every respect. In terms of English, there is no question of students on the reserves of utility, but there is a considerable problem. First, although college students have mastered a large amount of vocabulary and grammar knowledge, there is no enough practice in English communication. The learning mode of students and teachers is still conservative. The learning of English is only limited to the class with teachers explaining knowledge and students recording it. After conservative class, students are required to consolidate the knowledge they learn by completing exercises and assignments.

Second, relatively to the intensive course arrangement in high school, there is less course arrangement in the university. Due to the limited teaching time, it is unlikely for teachers take consideration to interpretation of knowledge and the efficiency to enhance students' English communicative competence within the specified time. Lack of interaction between students and teachers causes students as the main body of teaching activity to only passively receive knowledge and lead to the dull and boring classroom atmosphere. For a long time, students' enthusiasm for learning English is also weakened. Third, some of the teaching material content is outdated, which is bad for students to apply knowledge to social practice so that students will not be able to produce interest in learning the teaching content and also will not take an active part in English teaching activities, which also can produce negative effect on the following study of English course. Therefore, in order to keep up with the changes of the Times and the need of teaching reform and college English teaching mode must be reformed and a new teaching mode to improve English should be established.

\section{A. Unique value of MOOC}

MOOC integrates the information of new time and daily teaching and has integrated connotation. English teaching describe the teaching progress in a concentrated case. Aiming at all kinds of colleges and universities, English is classified as a compulsory subject, which is facing the difficult on how to get students fully involved into the subject. Daily English teaching should enable students to be fond of learning so as to match the nature of cultivating goals. For this purpose, the deep connotation of MOOC is compatible to the overall goal of English. From the perspective of model, MOOC characterizes a neoteric process carefully created out. It adopts the humanistic idea, selects the construction process and accepts program mode. Compared with traditional teaching, MOOC changes the traditional single model of teaching, creating interactive thinking.[4] When designing class activities and follow-up evaluation, it underlines the change and focuses on the subject, that is to say, the subject is developing into the most important one superior to what to teach. It also deconstructs the inherent behavior chain and expects to reconstruct and create more excellent new interactions. MOOC links the relationship between teachers and students on the platform and enrich resources to ensure the smooth linkage. Existing teaching cannot blindly follow the model. Instead, it should identify the deep connotation of MOOC. With the help of a new form, optimization in English teaching can be achieved. To build this kind of inquiry on the above research foundation should show its characteristics rooted in normal teaching.

\section{B. Connotation and value of "flipped classroom"}

Flipped classroom is an instructional strategy and a type of blended learning that reverses the traditional learning environment by delivering instructional content, often online, outside of the classroom. It moves activities, including those that may have traditionally been considered homework, into the classroom. In a flipped classroom, students watch online lectures, collaborate in online discussions, or carry out research at home and engage in concepts in the classroom with the guidance of a mentor [5].

\section{Addition of neoteric class process}

The flipped classroom intentionally shifts instruction to a learner-centered model in which class time explores topics in greater depth and creates meaningful learning opportunities, while educational technologies such as online videos are used to deliver content outside of the classroom. In a flipped classroom, content delivery may take a variety of forms. Often, video lessons prepared by the teacher or third parties are used to deliver content, although online collaborative discussions, digital research, and text readings may be used. Flipped classrooms also redefine in-class activities. In-class lessons accompanying flipped classroom may include activity learning or more traditional homework problems, among other practices, to engage students in the content. Class activities vary but may include: using math manipulatives and emerging mathematical technologies, in-depth laboratory experiments, original document analysis, debate or speech presentation, current event discussions, peer reviewing, project-based learning, and skill development or concept practice Because these types of active learning allow for highly differentiated instruction, more time can be spent in class on higher-order thinking skills such as problem-finding, collaboration, design and problem solving as students tackle difficult problems, work in groups, research, and construct knowledge with the help of their teacher and peers. Flipped classrooms have been implemented in both schools and colleges and been found to have varying differences in the method of implementation.

\section{Change of monotonous role}

In the traditional model of classroom instruction, the teacher is typically the central focus of a lesson and the primary disseminator of information during the class period. The teacher responds to questions while students defer directly to the teacher for guidance and feedback. In a classroom with a radically traditional style of instruction, individual lessons may be didactic and content oriented. Student engagement in the traditional model may be limited to activities in which students work independently or in small groups on an application task designed by the teacher. Class discussions are typically 
centered on the teacher, who controls the flow of the conversation. Typically, this pattern of teaching also involves giving students the task of reading from a textbook or practicing a concept by working on a problem set, for example, outside school. Flipped classroom clears the due position between teachers and students. It requires student to conduct analysis in the teachers' guidance. This will change the passive acceptance under the traditional ideas into conscious analysis. Potentials of students in the flipped classroom become independent. As a result, it facilitates the smooth follow-up communication to grasp more knowledge. Even this, however, does not reduce teachers' guidance. Guidance of teaching can be extended to the after school time to add guidance value[6].

\section{E. To resolve all kinds of difficulties}

Traditional teaching programs focus on consolidating the selected knowledge and passive memorization, which selects spoon-feeding way to let the students accept all the key difficulties the outline draws up and does not consider whether students can digest them or not. But in the flipped classroom, difficulties are screened out for further communication, paying attention to the interactive solutions. Through the smooth communication, new resolutions are figured out. This process has a clear guidance, by answering questions at the same time; it also adds the inherent discrimination ability and extends English thinking.

\section{FliPPED CLASSROOM TEACHING MODE EXPLORATION BASED ON MOOC}

\section{A. Video alternation}

MOOC draws a summary of the process which provides the flipped classroom and covers the video alternation, containing double stage. In the preparation before class, the teacher prepares the necessary video for students' watching. The independently formulated training topic replaces outline of the topic in the traditional path in order to get training. MOOC covers the summary of the process, the share of the available resources, the topic of each period, notification of each period and subject teachers' introduction. Through coordination, it can maintain course.

The teaching focuses on parsing the source of knowledge by the preparation of the micro video, micro courseware, associated case, project and experiment and complete sets of resources. It also sets online contact with the auxiliary category of answering questions and follow-up testing processes, adds online research and clears all kinds of opinions of feedback. According to the finished materials, teachers can identify the subject's own characteristics and English teaching system. Knowledge of the subjects can be then divided into multiple points through pieces of processing. Around pieces of knowledge, videos more suitable for the platform can be built up.

\section{B. To promote knowledge internalization}

In the established classroom, knowledge should be internalized. Flipped classroom pays attention to ascend the intrinsic cognitive results through the establishment situation to be internalized. In the largest category, students can connect a deep connotation with the aid of a good situation that set in class. The teachers and students are supposed to help each other to build a much smoother session. In view of the existing feedback, the difficult points in this session should be concluded. Combining with the subject system, students can challenge additional features of this kind of situation. Situation is up to cover the problem, setting training missions. Students according to their own interest tendency filter the project. In view of the students in class, they can be further divided into detailed learning groups with each group leader screened and task for each ground segmented. In view of the complex project, all the group members can finish together[7]. When conditions permit, they can select the process of field investigation and deepen their impression on the project.

\section{Personally prepare videos}

In some cases, students fail to find the most appropriate one within the video of screening out. At this time, in accordance with the tasks, students can personally add videos. After that, a new video can be prepared with difficult. QQ group with a certain category can also be established for the teacher always identifying doubt in homemade video cases and providing the necessary guidance. Thus, cognitive clues become much clearer and knowledge is more compacted.

\section{Feedback to teaching effect}

According to teaching demands, students conduct evaluation on teaching effect and propose suggestions so as to enable teachers to learn about the learning difficulties and acceptance degree of students and make adjustment and teaching procedure in a flexible way accordingly.

TABLE I. T EVALUATION ON TEACHING EFFECT FROM INDEX SYSTEMS

\begin{tabular}{|c|c|c|c|c|c|c|}
\hline Number & Index systems & Excellent & Good & General & Bad & Score \\
\hline 1 & \begin{tabular}{|l|} 
Curriculum content is \\
complete and regulated to \\
embody teaching purpose, \\
task, content and requirement
\end{tabular} & (4) & (3) & (2) & & \\
\hline 2 & Experimental teaching items & (4) & (3) & (2) & & \\
\hline 3 & $\begin{array}{l}\text { Curriculum teaching plan and } \\
\text { teaching situation tables }\end{array}$ & (4) & (3) & (2) & & \\
\hline 4 & $\begin{array}{l}\text { Structure and content } \\
\text { arrangement is reasonably } \\
\text { embodied in teaching plan }\end{array}$ & (4) & (3) & (2) & & \\
\hline 5 & $\begin{array}{l}\text { Key points and special } \\
\text { difficulties are specially } \\
\text { pointed out in teaching plan } \\
\text { and allocated reasonably }\end{array}$ & (4) & (3) & (2) & & \\
\hline 6 & $\begin{array}{l}\text { Familiar with teaching plan, } \\
\text { immediate revision and strict } \\
\text { execution of teaching plan }\end{array}$ & (4) & (3) & (2) & & \\
\hline 7 & $\begin{array}{l}\text { Reasonable selection of } \\
\text { teaching materials and } \\
\text { accordance with proposal } \\
\text { requirements }\end{array}$ & (4) & (3) & (2) & & \\
\hline 8 & $\begin{array}{l}\text { Familiar with teaching } \\
\text { environment and well- } \\
\text { prepared for related teaching } \\
\text { facilities }\end{array}$ & (4) & & & & \\
\hline Eva & luation and suggestion: & Total & \multicolumn{3}{|c|}{ Average score: } & \\
\hline
\end{tabular}




\section{CONCLUSION}

Flipped college English classroom teaching mode based on MOOC caters to the core of the guiding ideology in the Chinese education informatization development. It in addition to teaching students knowledge exercises their ability of selfstudy and comprehensive personal competence, which is correspondent to what have been exploring as the quality education concept.

In addition, this kind of teaching mode is in line with the construction goal and mission requirements of high-quality education resource sharing, aiming to promote the education teaching idea transformation, leading the teaching content and teaching method reform, promoting the high quality teaching resources sharing through modern information technology in colleges and universities and improving the quality of personnel training service and construction of learning society.

The most important is, it truly achieves the "studentcentered" teaching design concept, fully embodies the subject status of students in teaching and the dominant role of teachers in the teaching and is in line with the teaching purpose proposed in "college English curriculum requirements" to promote the formation of students' individualized learning and the development of students' autonomous learning ability.

\section{REFERENCES}

[1] Riter's Handbook. Mill Valley, CA: University Science, 1989.

[2] Kathleen F. Upside Down and Inside Out: Flip Your Classroom to Improve Student Learning[J].Learning and Leading with Technology,2012(6)

[3] Pan Li. Zhang Guoyun. Li Wu. MOOC flipped classroom teaching mode exploration[J].China's education informationization.2015(02):16-18.

[4] Li Z.,Link S.,Ma H.,Yang H.,Hegelheimer V. The role of automated writing evaluation holistic scores in the ESL classroom[J]. System,2014( 44)

[5] Wang Lu. The exploration and application flipped classroom teaching mode based on MOOC in college English teaching class[J].Journal of higher learning research,2015(9)

[6] Sams A. Bergmann J. Flip Your Students' Learning[J].Educational Leadership,2013( 3)

[7] Li Manli. The characteristic and teaching design exploration of MOOC[J].Research On Education Tsinghua University,2013( 8)

[8] Ma Wulin,Hu Jiasheng. The impact and reconstruction of international MOOC on the college English curriculum in our country[J]. Computerassisted foreign language education,2014(3) 